\title{
ESTRATÉGIAS METODOLÓGICAS PARA INVESTIGAR A PROSÓDIA DO FOCO NO PORTUGUÊS BRASILEIRO
}

\author{
Daise Ribeiro Pereira CARPES ${ }^{1}$ \\ Izabel Christine SEARA ${ }^{2}$
}

\begin{abstract}
Resumo: O presente artigo discute a montagem de corpora para análise prosódica dos focos não exaustivo, exaustivo e contrastivo em português brasileiro. São descritas aqui as metodologias de experimentos de produção e percepção criados para investigar e descrever a prosódia da fala e a prosódia visual de sentenças declarativas com os três tipos de focos anteriormente mencionados, considerando-se a hipótese de que haja diferentes comportamentos prosódicos para diferentes tipos de foco. É feita uma descrição metodológica dos experimentos já realizados bem como a descrição dos primeiros resultados encontrados e das próximas etapas experimentais.
\end{abstract}

Palavras-chave: Fonética. Prosódia. Foco. Prosódia visual. Linguística Experimental.

\section{Considerações iniciais}

Na busca de entendimento sobre o foco no português brasileiro com ênfase na prosódia, realizamos vários experimentos de produção e de percepção para os quais desenvolvemos metodologias. É o desenvolvimento dessas metodologias, tão caras aos estudos prosódicos, que discutiremos neste texto. À época do início de nossa pesquisa (2013), não encontramos estudos que pudessem nos auxiliar na montagem dessas

\footnotetext{
${ }^{1}$ UFSC - Universidade Federal de Santa Catarina - Programa de Pós-graduação em Linguística/Bolsa CAPES. Florianópolis - Santa Catarina - Brasil. 88040-900 - daiseribeiro@gmail.com

${ }^{2}$ UFSC - Universidade Federal de Santa Catarina - Departamento de Língua e Literatura Vernáculas. Programa de Pós-graduação em Linguística/Bolsa CNPq. Florianópolis - Santa Catarina - Brasil. 88040900 -izabels@linse.ufsc.br
}

http://dx.doi.org/10.21165/gel.v14i2.1588 
metodologias, nem mesmo bibliografia abundante que abordasse o tema ${ }^{3}$ - foco não exaustivo, nosso objeto de pesquisa - no português brasileiro (doravante PB). Dessa forma, elaboramos uma metodologia de pesquisa e montamos um corpus de análise inédito para investigar esse tema.

Nosso objeto de pesquisa era o foco não exaustivo, e nossa hipótese era a de que há uma curva de F0 específica para esse tipo de foco, podendo ser confirmada ou não, que o diferenciaria dos demais tipos. Para sabermos se havia uma curva prosódica exclusiva ou não, era preciso comparar o foco não exaustivo com outros tipos de foco. Portanto, nossos experimentos acabaram por avaliar a prosódia de três tipos de foco: não exaustivo, exaustivo e contrastivo.

Nosso ponto de partida foi um artigo sobre foco não exaustivo na língua basca (ELORDIETA; IRURTZUN, 2010), e foi a partir dele que usamos a nomenclatura adotada em nossa pesquisa (focos não exaustivo, exaustivo e contrastivo). Pesquisando a literatura sobre foco, percebemos que esses três tipos de focalização podem ser também nomeados como foco de informação - o equivalente ao foco não exaustivo; foco de identificação - o equivalente ao foco exaustivo; foco de correção - o equivalente ao foco contrastivo (KISS, 1998; ZUBIZARRETA, 1998; MIOTO, 2003; MENUZZI, 2012). ${ }^{4}$

Nossa estratégia, então, foi montar um experimento piloto, por meio do qual pudéssemos testar a metodologia proposta. Como estávamos criando uma metodologia, fizemos essa rodada piloto, constituída de um experimento de produção e dois de percepção, para identificar possíveis problemas metodológicos (CARPES; SOSA; SEARA, 2013). Na sequência, fizemos uma nova rodada de experimentos com ajustes e melhorias a partir dos resultados obtidos nos pilotos (CARPES; SOSA; SEARA, 2014; CARPES, 2014).

Os resultados dos experimentos realizados nos levaram a perceber que havia necessidade de investigação de uma outra variedade prosódica: a visual. Para investigar se a prosódia do foco é marcada não só na fala, mas também nas expressões faciais e

\footnotetext{
${ }^{3}$ Para um panorama mais recente das pesquisas experimentais nessa área no Brasil, remetemos o leitor aos textos de Moraes, Carnaval e Coelho (2015) e Carnaval (2017).

${ }^{4}$ Moraes (2006) utiliza classificação e nomenclatura distintas, a saber: focalização neutra (quando uma asserção meramente fornece informação solicitada em pergunta prévia), focalização contrastiva com valor exclusivo (equivalente ao que chamamos de foco contrastivo) e focalização contrastiva com valor não exclusivo (quando o falante corrige uma asserção do interlocutor, mas com pouca ênfase, assumindo a possibilidade de verdade simultânea entre as duas asserções).
} 
corporais do falante, elaboramos outras estratégias metodológicas, que serão também aqui apresentadas.

Para melhor descrevermos as metodologias propostas, iniciaremos explicitando o que são os focos estudados. Foco não exaustivo é aquele em que a sentença é verdadeira, mas não é a única verdade possível, ou seja, não exclui outras afirmações como verdadeiras para a mesma questão. Veja o exemplo no par pergunta-resposta em (1):

(1) (a) - O que tinha no cardápio do Restaurante Universitário hoje?

(b) - Tinha BIFE ACEBOLADO. ${ }^{5}$

A sentença (1b) tem foco não exaustivo, pois ela é verdadeira (de fato, foi servido bife acebolado no almoço), mas não é exaustiva, pois havia outros alimentos no cardápio de almoço do restaurante, como arroz, feijão, salada etc.

O foco exaustivo, no entanto, é aquele cuja sentença que o veicula exclui quaisquer outras possibilidades de afirmação para a mesma questão. Veja o exemplo no par pergunta-resposta em (2):

(a) - Como se chama o marido da Marcela?

(b) - Ele se chama JÚLIO.

A sentença $2 b$ tem foco exaustivo, já que a Marcela tem apenas um marido, e o nome dele é Júlio, ou seja, essa é a única resposta verdadeira para a questão.

Por fim, o foco contrastivo está presente em sentenças cujo conteúdo corrige ou contraria uma afirmação ou um pressuposto do interlocutor. Veja o exemplo em (3):

(3) (a) - O Carlos comprou um carro novo.

(b) - O MÁRCIO comprou um carro novo (não o Carlos).

A sentença $3 b$ tem foco contrastivo, pois corrige a afirmação do interlocutor em $3 a$.

\footnotetext{
${ }^{5}$ As palavras grafadas em letras maiúsculas destacam o sintagma focalizado das sentenças.
} 
Sobre a marcação do foco pela prosódia, alguns estudos, como Menuzzi (2012), indicam que o papel da prosódia seria apenas marcar o sintagma focalizado, mas que ela não seria capaz de indicar o tipo de foco, pois esse seria um fenômeno pragmático. Nossa hipótese, porém, é de que a prosódia, combinada à sintaxe e à pragmática, tem um peso importante não apenas na marcação e na identificação do sintagma focalizado em uma sentença (já que investigamos apenas foco do tipo estreito, narrow focus - em oposição a foco amplo, broad focus, que é quando o foco recai sobre toda a sentença, e não sobre um sintagma (FROTA, 2000) -, mas também na marcação e na identificação do tipo de foco). Os experimentos que já realizamos nos dão indícios de que essa hipótese parece ser adequada.

$\mathrm{Na}$ sequência, apresentamos os procedimentos metodológicos empregados nos experimentos de produção e de percepção que realizamos na busca do entendimento da prosódia dos focos não exaustivo, exaustivo e contrastivo.

\section{O experimento piloto de produção}

O primeiro experimento piloto de produção consistiu em coletar gravações com falas de informantes produzindo sentenças com os três tipos de focalização (não exaustiva, exaustiva e contrastiva). A partir da análise desses dados, foi investigado se havia diferenças prosódicas entre essas três produções que pudessem distingui-las entre si, e se as produções de cada tipo de foco podiam ser identificadas apenas pela prosódia.

Para esse experimento piloto de produção, foi criado um corpus composto de quatro sentenças, todas obedecendo ao seguinte padrão sintático: sujeito + verbo + objeto - SVO:

Sentença 1: O João come CAMARÃO.

Sentença 2: $O$ Vitor ouve PAGODE.

Sentença 3: $O$ Pedro toma CERVEJA.

Sentença 4: $O$ Kaká marcou UM GOL. ${ }^{6}$

Todas as sentenças tinham foco no objeto, que é o sintagma mais encaixado da sentença e que, sendo constituído por apenas uma palavra acentuada, é o locus para a

\footnotetext{
${ }^{6}$ As palavras em caixa alta representam o sintagma focalizado em cada sentença.
} 
associação do acento nuclear ${ }^{7}$ (LADD, 2008). Cada uma das sentenças era repetida três vezes, sendo uma repetição para cada tipo de foco em estudo. Dessa forma, o corpus coletado seria composto de sentenças com o mesmo conteúdo segmental e a mesma ordem sintática, para que assim pudéssemos eliminar variáveis lexicais e sintáticas e nos restringir a diferenças prosódicas.

Para a produção de cada sentença, era apresentado em áudio um contexto que situava o informante, e então ele produzia a sentença-alvo. Buscávamos com isso o máximo de naturalidade nas produções dos informantes, e os informantes eram assim orientados. Apresentamos abaixo, em (4), o contexto criado para a produção da sentença O Kaká marcou um gol com foco não exaustivo:

(4) Ontem teve jogo do Uruguai contra o Brasil. Ao chegar ao trabalho hoje, o Roberto me perguntou quantos gols foram marcados na partida. Eu só assisti ao primeiro tempo e vi o gol do Kaká, mas não sei se houve mais gols no segundo tempo, então lhe disse:

- O Kaká marcou UM GOL.

A metodologia de coleta foi do tipo fala semiespontânea. Devido às características que buscamos analisar e às suas especificidades, os informantes foram expostos a estímulos auditivos - contextos narrativos que indicavam qual o tipo de foco da sentença que eles produziriam em seguida. Após ouvir cada um desses estímulos, os informantes deveriam produzir as sentenças do nosso corpus, que apareciam escritas na tela do experimento. As sentenças a serem produzidas deveriam ser lidas como se os informantes fizessem parte daquele contexto narrativo. Depois, passavam para um outro contexto e produziam a sentença correspondente - os conjuntos de contextos com as respectivas sentenças eram apresentados de forma aleatória. Com essa estratégia, buscamos inserir os participantes na situação apresentada, para que sua elocução fosse a mais natural possível.

\footnotetext{
${ }^{7} \mathrm{O}$ acento nuclear é o mais proeminente da sentença e inclui, além do acento tonal na sílaba tônica, o tom de fronteira, alinhado ao final da pós-tônica. Numa sentença sem foco, ele recai sobre a última sílaba acentuada. Numa sentença com foco, ele coincide com a sílaba tônica da palavra focalizada.
} 
Quando o objeto de análise é um fenômeno cujo controle experimental exige a presença de um conjunto de sentenças improvável de se coletar espontaneamente, dada a sua particularidade sintática, morfológica ou mesmo fonética, vemo-nos forçados a montar um experimento usando ou a fala lida ou a fala semiespontânea. (SEARA; FIGUEIREDO-SILVA, 2007, p. 2).

Sabe-se que há diferenças na produção de sentenças em fala espontânea, semiespontânea e lida. Na fala espontânea, os informantes têm mais liberdade para escolher os eventos tonais que utilizam em suas elocuções (ESSER, 1988 apud SEARA; FIGUEIREDO-SILVA, 2007). A complexidade em se realizar pesquisas com fala espontânea vai além da dificuldade de se conseguir número suficiente de dados que sejam homogêneos em sua estrutura. Isso porque, no nível entoacional, a alteração da tipologia verbal, do sintagma nominal ou mesmo da posição dos sintagmas na sentença pode levar a mudanças nos contornos da curva de $\mathrm{F}^{8}{ }^{8}$. Depois de ouvido o contexto narrativo, os informantes produziam a sentença com a entoação que julgassem mais adequada para o contexto narrativo apresentado em áudio.

A coleta de dados deu-se em laboratório, num ambiente controlado e sem ruídos; os informantes poderiam ouvir os contextos novamente se achassem necessário. Também lhes era dada a opção de repetir a gravação caso achassem que sua primeira produção não saíra como esperavam. A coleta dos dados consistia nos seguintes passos:

1) Aparecia escrita, no alto da tela do computador, a sentença que os informantes deveriam produzir (Figura 1).

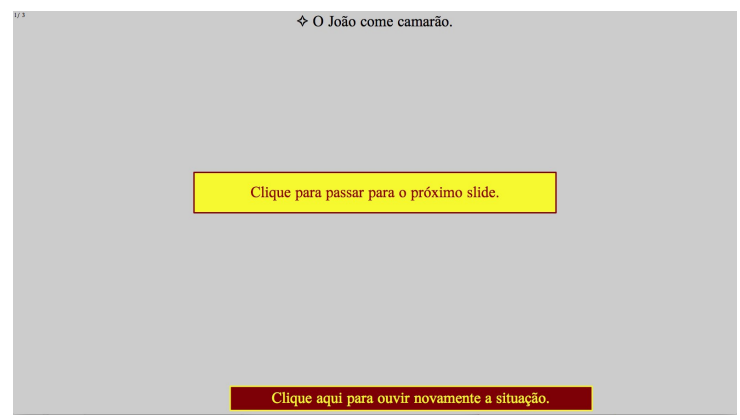

Figura 1: Tela com o estímulo para o experimento piloto de produção na parte superior. A sentença a ser produzida pelo informante era "O João come camarão"

\footnotetext{
${ }^{8} \mathrm{O}$ contorno da curva de F0 corresponde aos valores da frequência fundamental obtidos na extensão da sentença proferida pelo informante.
} 
2) Enquanto isso, o informante ouvia o contexto e, em seguida, produzia a sentença de forma a estar adequada ao contexto que acabara de ouvir, enquadrando assim a sentença em um tipo de foco (aquele sugerido pelo contexto ouvido).

Participaram desse experimento piloto de produção oito informantes, três homens e cinco mulheres, com idades entre 21 e 40 anos e nível universitário (entre graduação em andamento e doutorado completo), o que resultou num total de 96 sentenças -8 sujeitos $\times 4$ sentenças $\times 3$ tipos de foco. Os recursos usados para a coleta de dados foram um computador MacBook e os softwares Praat ${ }^{9}$ e Ocenaudio ${ }^{10}$, em suas versões para Mac. Nessa etapa não foi feito nenhum controle sobre sexo ou dialeto dos falantes, algo que será controlado nas próximas etapas da pesquisa.

Os resultados desse experimento foram analisados, e assim identificamos:

- Para as sentenças com foco não exaustivo, dois tipos de curva (Figuras 2a e $2 b)$;

- Para as sentenças com foco exaustivo, três tipos de curva, sendo que duas delas tinham alguma configuração em comum com as de foco não exaustivo (2c e $2 d$ ) e outra que tinha configuração bastante diferente (2e);

- Para as sentenças com foco contrastivo, dois tipos de curvas de F0: uma com padrão que se assemelhava ao das curvas com foco não exaustivo ( $2 \mathrm{a}$ e $2 \mathrm{~b}$ ) e outra com padrão que se assemelhava ao das curvas com foco exaustivo diferente dos padrões das curvas de foco não exaustivo $(2 \mathrm{e})^{11}$.

\footnotetext{
${ }^{9}$ Praat: doing phonetics by computer - Esse software foi desenvolvido por Paul Boersma e David Weenik e pode ser obtido livremente em: $<$ http://praat.org $>$.

10 Esse software foi desenvolvido por Rui Seara Jr. e pode ser obtido livremente em: $<$ http://ocenaudio.com.br $>$.

${ }^{11}$ Para mais detalhes sobre os resultados destes experimentos, remetemos o leitor aos textos Carpes, Sosa e Seara (2013) e Carpes (2014).
} 
(a)

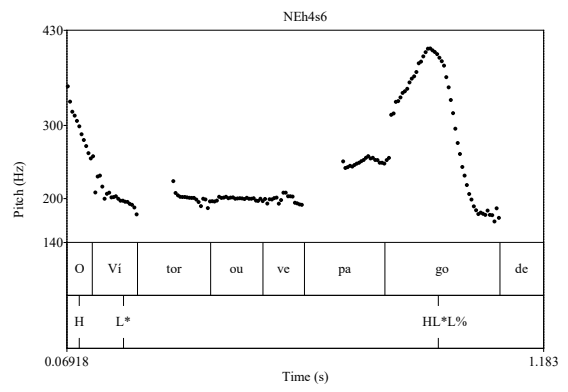

(c)

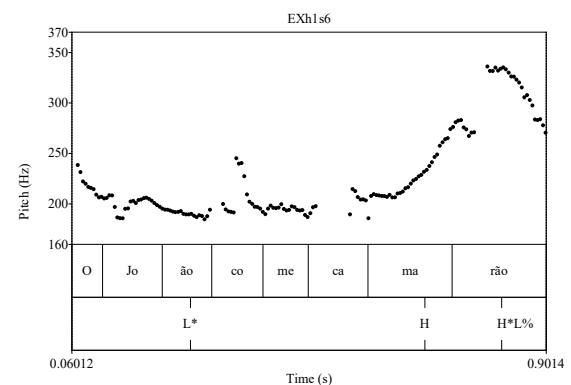

(b)

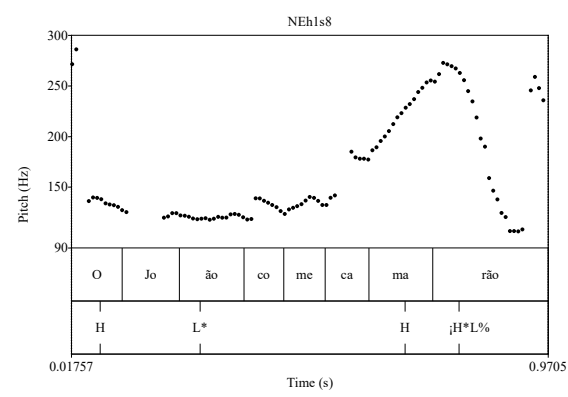

(d)

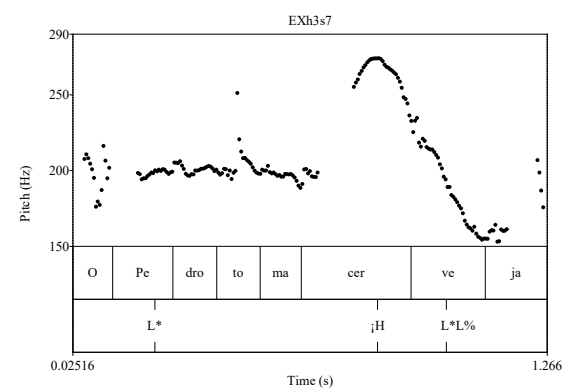

(e)

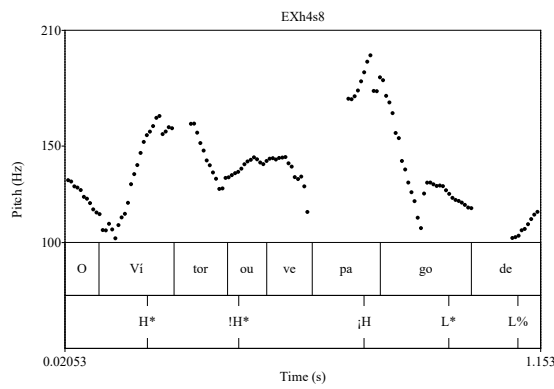

Figura 2: Exemplos de comportamentos entoacionais identificados no experimento piloto de produção para sentenças com focos não exaustivo ( $2 \mathrm{a}$ e $2 \mathrm{~b}$ ), exaustivo ( $2 \mathrm{c}$ e $2 \mathrm{~d}$ ) e contrastivo (semelhante a $2 \mathrm{a}, 2 \mathrm{~b}$ e $2 \mathrm{~d}$ )

No entanto, foi observado um problema concernente ao experimento de produção que dizia respeito ao corpus, mais precisamente aos contextos criados para a produção das sentenças. Notamos que, do ponto de vista sociolinguístico, os contextos pareciam muito "formais" e com fortes características de texto escrito. Vejamos o trecho de um dos contextos, que se utiliza de um pronome pouco empregado na fala coloquial em (5):

(5) “[...] mas não sei se houve mais gols no segundo tempo, então lhe disse". 
Os contextos eram apresentados de forma oral, ou seja, os participantes ouviam os contextos, porém, esses contextos não soavam tão naturais como esperávamos.

Outros dois problemas foram observados nos contextos:

(a) como os itens que fizeram parte dos núcleos prosódicos eram constituídos de palavras com pós-tônica (por exemplo, cerveja) e sem postônica (por exemplo, camarão), houve certa dificuldade para a indicação de compressão ou truncamento do contorno final quando o núcleo era composto por oxítonas ou por monossílabos tônicos devido à falta de material segmental para suportar o acento tonal e o tom de fronteira;

(b) como o foco estava localizado em uma região do enunciado default para a marcação de um evento tonal, talvez isso tenha colaborado para a identificação da manifestação do foco.

\section{Os experimentos piloto de percepção}

Para que pudéssemos validar os resultados do experimento de produção, montamos dois experimentos piloto de percepção.

Os experimentos de percepção aqui montados constituem uma etapa fundamental da nossa metodologia, pois a validação dos dados seria feita não pelos pesquisadores, mas por sujeitos que não estão envolvidos com a elaboração da pesquisa e de suas hipóteses. Para isso, as sentenças gravadas pelos nossos informantes (aquelas com os tipos de curvas de F0 que correspondiam aos focos estudados) eram apresentadas a outros informantes, agora nomeados como ouvintes. Esses ouvintes deveriam relacionar ou não as curvas de F0 das sentenças coletadas ao tipo de foco para o qual foram produzidas. Se os ouvintes estabelecessem uma correlação com base apenas na prosódia, isso iria ao encontro da nossa hipótese de que a prosódia sozinha seria capaz de marcar o sintagma focalizado e indicar o tipo de foco da sentença. Participaram do experimento quatro ouvintes, todos universitários e nascidos na região da Grande Florianópolis, sendo três mulheres e um homem, com idades entre 23 e 48 anos.

O primeiro experimento piloto de percepção pretendia verificar se os comportamentos prosódicos identificados como mais recorrentes para cada um dos 
focos seriam assim percebidos pelos ouvintes, ou seja, se os ouvintes seriam capazes de, apenas pela prosódia, identificar o tipo de foco veiculado na sentença. Ou se a diferença entre os três tipos de foco estaria em outros fatores necessários para a sua adequada identificação e interpretação, tais como a necessidade da introdução de itens lexicais como "pelo menos" (para foco não exaustivo), "só" (para foco exaustivo) e "não" (para foco contrastivo).

Como se tratava de um experimento de percepção piloto, que pretendia testar a metodologia de pesquisa, escolhemos apenas uma das sentenças coletadas e seus respectivos contextos para apresentar aos ouvintes. Não testamos, nessa etapa, todas as sentenças coletadas no experimento de produção para agilizar a avaliação da metodologia e poder partir para uma nova rodada de experimentos.

Neste experimento de percepção, os ouvintes ouviam os mesmos contextos que foram apresentados aos informantes no experimento de produção. $\mathrm{Na}$ sequência, ouviam duas sentenças-estímulo em fala natural produzidas pelos informantes no experimento de produção. Em seguida, os ouvintes optavam por uma de quatro opções (Sentença 1; Sentença 2; Qualquer sentença; Nenhuma delas), apresentadas na tela do computador, conforme Figura 3 (em amarelo). Era dada ainda aos ouvintes a possibilidade de ouvir novamente o contexto antes de fazerem suas escolhas.

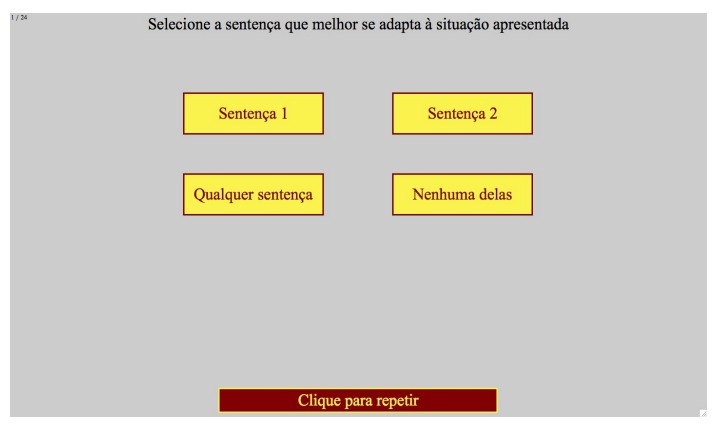

Figura 3: Tela apresentada aos participantes do primeiro experimento piloto de percepção

As sentenças que compuseram o experimento de percepção foram aquelas que mais bem representavam as curvas de F0 identificadas na análise do experimento de produção.

Assim, se o ouvinte selecionasse a opção "Sentença 1", isso queria dizer que a primeira sentença era a mais adequada para o contexto ouvido; se selecionasse a opção 
"Sentença 2", isso queria dizer que a segunda sentença era a mais adequada para o contexto ouvido; se selecionasse a opção "Qualquer sentença", isso queria dizer que ambas as sentenças seriam adequadas ao contexto ouvido e, por fim, se selecionasse a opção "Nenhuma delas", isso queria dizer que nenhuma delas era adequada ao contexto ouvido. Os equipamentos utilizados foram um computador MacBook e o software Praat.

O segundo experimento piloto de percepção foi montado a partir dos mesmos dados coletados previamente, mas buscamos agora testar questões prosódicas relacionadas ao comportamento da duração relativa ${ }^{12}$ das sílabas que compõem o núcleo entoacional da sentença. O núcleo entoacional é o elemento que assume a posição prosodicamente mais proeminente no domínio da sentença. Quando a sentença tem foco estreito, como os casos que estamos estudando, o núcleo entoacional coincide com a palavra ou os constituintes focalizados, já que estes recebem o acento principal da sentença. Dessa vez, a escolha das sentenças foi feita com base em características relacionadas à duração relativa da sílaba tônica do núcleo entoacional das sentenças, ou seja, do objeto complemento do verbo, que era o sintagma focalizado. As sentenças foram classificadas de acordo com três configurações de duração: uma em que a duração relativa das sílabas que compunham o núcleo entoacional era semelhante; outra em que a duração relativa da sílaba tônica que compunha o núcleo entoacional era mais longa do que as demais sílabas do núcleo; e uma terceira em que a sílaba pré-tônica do núcleo entoacional tinha duração relativa mais longa do que as demais sílabas do núcleo ${ }^{13}$. O teste apresentava em ordem aleatória 26 combinações de pares de sentenças.

A metodologia do segundo experimento piloto de percepção foi igual à do primeiro, ou seja, o participante ouvia um contexto narrativo seguido de duas produções da mesma sentença e escolhia uma das quatro opções de resposta apresentadas anteriormente (Figura 2). Dessa vez, participaram do experimento de percepção 14 ouvintes (13 catarinenses e um mineiro), sendo duas mulheres com ensino superior em andamento e cinco com ensino superior completo; e sete homens com ensino superior completo. Os ouvintes tinham idades entre 27 e 46 anos.

\footnotetext{
${ }^{12}$ A duração relativa foi calculada tomando como base a duração do que constitui o núcleo entoacional. Assim, duração relativa $=($ duração da sílaba $/$ duração do núcleo entoacional $) \times 100$. Esse cálculo permite comparar proporcionalmente a duração das sílabas que compõem o núcleo entoacional.

13 Salientamos ainda que a sílaba pós-tônica também pode sofrer alongamento quando em final de enunciado (pré-fronteira) (SERRA, 2009).
} 
Em resumo, a diferença entre o primeiro experimento piloto de percepção e o segundo era o que estávamos testando e observando. No primeiro, testamos a identificação das curvas de F0. No segundo, testamos a relação entre os tipos de foco e a duração relativa das sílabas que compunham o núcleo entoacional das sentenças focalizadas, aqui considerando indistintamente todas as curvas identificadas para cada tipo de foco.

\section{Resultados dos experimentos piloto de percepção}

Os resultados do primeiro experimento piloto de percepção apontam que grande parte dos ouvintes relacionou a curva de F0 de sentenças com foco não exaustivo com os contextos de não exaustividade, que era o que esperávamos. A relação que os ouvintes estabeleceram entre contextos e sentenças com foco exaustivo e contrastivo, porém, não foi tão bem-sucedida. Havia duas possibilidades para justificar esses resultados: uma seria que a nossa hipótese de que apenas a prosódia era suficiente para marcar cada um dos três tipos de foco não estaria correta; outra possibilidade seria a de que os experimentos necessitariam de ajustes para que encontrássemos resultados mais precisos e confiáveis. Por isso, fizemos alterações na metodologia de coleta de dados para gerarmos uma nova rodada de experimentos.

Já a análise dos resultados do segundo experimento piloto de percepção parece indicar que as relações de duração entre as sílabas do núcleo entoacional podem ser um parâmetro relevante na interpretação dos focos em estudo. Os resultados demonstram que os ouvintes relacionaram ao contexto de foco não exaustivo sentenças cuja sílaba tônica da palavra focalizada se apresentava mais longa do que as demais sílabas dessa palavra, mesmo quando a sentença testada era a de uma curva entoacional produzida para uma situação de foco diferente (mas com traços em comum com a curva de F0 da não exaustividade). Quando o contexto apresentado era o de foco exaustivo, a maioria dos participantes escolhia como adequadas as sentenças com duração relativa equivalente entre as sílabas da palavra focalizada. Em situação de contrastividade, a escolha era sobre sentenças que apresentavam ou durações equivalentes ou pré-tônicas mais longas. 


\section{Os experimentos subsequentes - Críticas ao experimento piloto de produção}

Depois de realizarmos os experimentos piloto de produção e de percepção e, com eles, testarmos a metodologia de pesquisa, fizemos uma nova rodada de testes com alguns ajustes e melhorias, levando em conta os resultados obtidos com esses experimentos piloto.

A primeira mudança foi fazer a nova coleta dos dados de produção com um grupo mais homogêneo de participantes, buscando eliminar possíveis variáveis sociolinguísticas. Os informantes nessa etapa da pesquisa foram cinco mulheres, com nível superior completo (na área de Letras), com idades entre 23 e 32 anos, da região da Grande Florianópolis. Assim, acreditamos poder coletar dados mais consistentes, de um grupo de falantes da mesma região dialetal, haja vista a variabilidade entoacional observada em todo o Brasil (CARDOSO et al., 2014), fato não controlado no primeiro experimento piloto de produção.

$\mathrm{Na}$ etapa de análise dos dados do experimento piloto de produção, notamos que alguns aspectos do corpus também precisavam ser modificados e mais controlados. Assim, foram criadas novas sentenças para serem gravadas, já que o primeiro corpus era composto de sentenças com muitos segmentos não vozeados, o que dificultava a análise da frequência fundamental, uma vez que segmentos não vozeados não produzem pulsos glotais e também causam efeitos microprosódicos na cadeia da fala e interrupções na linha que representa a curva de F0 (ver Figura 4).

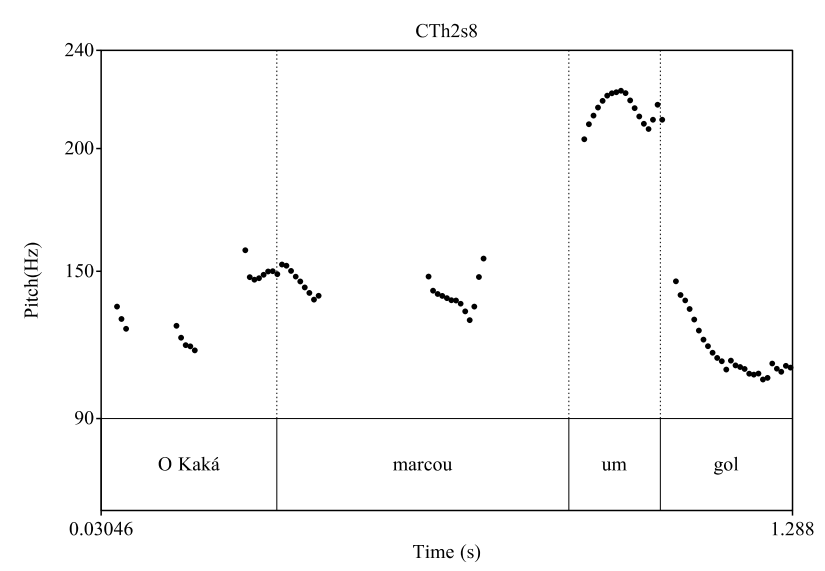

Figura 4: Curva de F0 da sentença "O Kaká marcou um gol” dita por um dos informantes: há falhas no traçado da curva provenientes dos segmentos não vozeados da sentença 
Também houve maior controle sobre aspectos concernentes à quantidade de sílabas das palavras que constituíam as sentenças. No experimento piloto, as sentenças tinham palavras de duração e acentos diferentes, o que dificultava a comparação entre elas. Por exemplo, no piloto todas as palavras focalizadas eram objeto complemento do verbo, mas duas eram paroxítonas; duas, oxítonas; três tinham três sílabas e uma tinha apenas uma sílaba (as palavras eram: camarão, pagode, cerveja, gol). Nas demais palavras das sentenças (sujeito e verbo) também havia variações desse tipo. Isso pode ter trazido complicações para nossa análise, pois essas características segmentais influenciam o formato da curva de F0. Posições diferentes de sílaba tônica nas palavras influenciam a posição do pico da curva entoacional e isso também dificultava a comparação entre diferentes sentenças com o mesmo tipo de foco. Dessa forma, no novo experimento de produção, todas as palavras que comporiam as sentenças teriam o mesmo número de sílabas (três) e acento na mesma posição (paroxítonas).

Veja a Figura 5, apresentando as curvas de duas sentenças do primeiro experimento piloto de produção. Em 5a, temos uma sentença que termina com uma palavra oxítona; em 5 b, temos uma sentença que termina com uma palavra paroxítona. Ambas as sentenças foram produzidas para contextos de não exaustividade, mas suas configurações de curva são diferentes, pois o pico entoacional muda em função da posição do acento da palavra.

(a)

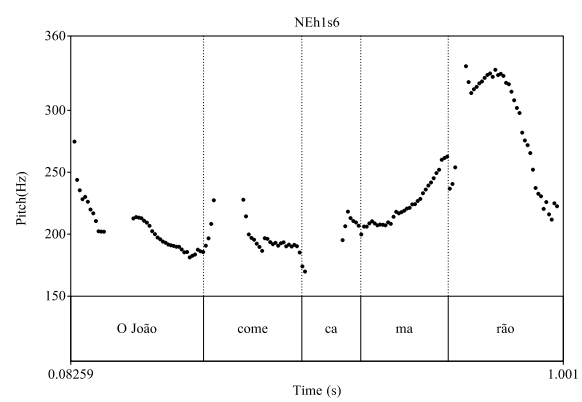

(b)

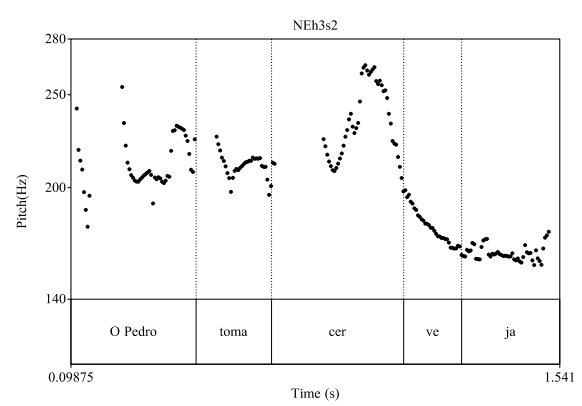

Figura 5: Em (a), sentença terminada em oxítona: o pico da curva de F0 está na última sílaba (tônica). Em (b), sentença terminada em paroxítona: o pico da curva de F0 está na antepenúltima sílaba (pré-tônica). As sentenças correspondem a contextos não exaustivos 
Na Figura 5, pode-se perceber que, apesar de termos duas sentenças com foco não exaustivo no objeto complemento do verbo, que é a última palavra da sentença, elas têm configurações de curva de F0 diferentes por causa da tonicidade dessa última palavra.

Como pudemos notar, essa falta de controle sobre o número de sílabas, a posição do acento e a sonoridade dos segmentos (se vozeados (sonoros) ou não) dificultou a análise do corpus do experimento piloto, razões pelas quais decidimos criar um novo corpus com mais controle sobre tais aspectos.

Decidimos ainda testar o foco no sujeito além do objeto complemento do verbo, para investigar se o comportamento prosódico seria mantido mesmo se a palavra focalizada estivesse em outra posição na sentença.

Assim, até o número de palavras (e, no limite, de sílabas) nas sentenças-alvo deveria ser semelhante: por exemplo, Frota e Vigário (1999 apud Tenani, 2002: 33), investigando os tipos de eventos tonais no início da frase entoacional, colocam que "a presença de um evento tonal está relacionada ao número de sílabas pretônicas da palavra inicial de $\Phi$ [sintagma fonológico]”. (SEARA; FIGUEIREDOSILVA, 2007, p. 3).

Com essas alterações definidas, coletamos novos dados para investigação.

\section{Corpus do novo experimento de produção}

Para compor o novo corpus, foram criadas quatro novas sentenças, sendo duas para cada posição de foco (sujeito e complemento).

Sentença 1: A CARINA escreve a novela.

Sentença 2: O RENATO ensina História.

Sentença 3: O Marcelo carrega AS CADEIRAS.

Sentença 4: A Michele desenha PROJETOS.

Para cada sentença havia três contextos referentes aos três tipos de foco em investigação. Cada informante gravou 12 sentenças, totalizando 60 sentenças coletadas para análise (12 sentenças gravadas por cinco informantes). Apresentamos em (6) o contexto criado para a produção da sentença $A$ Carina escreve a novela, com foco não exaustivo. 
(6) Eu comentei com a minha vizinha que tenho alguns amigos que escrevem a novela das seis pra televisão. Ela me perguntou se ela conhece algum deles. Eu sei que ela conhece pelo menos a Carina, mas não sei se ela conhece mais algum desses escritores, então eu disse:

- A Carina escreve a novela.

\section{A normalização dos dados coletados}

Quando analisamos as curvas de F0 dessas 60 sentenças, com o software Praat, os valores das escalas verticais em que as curvas eram projetadas no espectrograma variavam de uma para outra, pois as referências eram valores particulares de cada falante, dados em hertz. E assim, os valores das escalas verticais eram ajustados para cada curva individualmente. Porém, dessa forma, não conseguíamos comparar as curvas de maneira uniforme. Era preciso primeiro normalizar, de modo a obtermos números que fossem equivalentes nas produções, independentemente de seus valores absolutos em hertz. Após essa reflexão, geramos novamente a visualização das curvas, só que agora com os valores normalizados em semitons,

[...] tornando possível a comparação de distâncias de frequências, independentemente do valor absoluto em hertz que venham a assumir. Nesse sentido estaríamos avaliando a grandeza destas distâncias, ao invés dos valores absolutos, o que permitiria a comparação de duas curvas entoacionais diferentes, entoadas por dois falantes distintos, por exemplo. (T'HART et al., 1990 apud MARTINS; FERREIRA NETTO, 2010, p. 292).

A medida em hertz está ligada aos valores da frequência fundamental da voz, que são particulares para cada pessoa. A medida normalizada em semitons nos ajuda a comparar curvas de falantes diferentes. Quantitativamente, o aumento em um semitom corresponde aproximadamente a um aumento de $6 \%$ na frequência. Assim, o uso de uma escala vertical em semitons permite comparar as curvas de diferentes falantes, o que não pode ser feito com as escalas em hertz.

A curva com escala em semitons foi obtida a partir de um processo de normalização realizado pelo próprio software Praat. Essa conversão possibilitou a observação somente das diferenças referentes aos movimentos da curva de F0 
concernentes aos focos em estudo. Essas diferenças que estamos descrevendo podem ser vistas nas Figuras 6a e 6b, que mostram duas curvas de F0 de sentenças semelhantes sobrepostas, produzidas por dois falantes diferentes. Na Figura 6a, as duas curvas apresentam sua configuração particular de range ${ }^{14}$ em hertz. Percebe-se, pelos valores no eixo vertical, que elas estão em proporções diferentes, e, por conta disso, a comparação entre elas não pode ser feita adequadamente. Já na Figura 6b, as curvas foram normalizadas, apresentando a mesma escala vertical. Dessa forma, a comparação entre seus ranges pode ser realizada adequadamente.

(a)

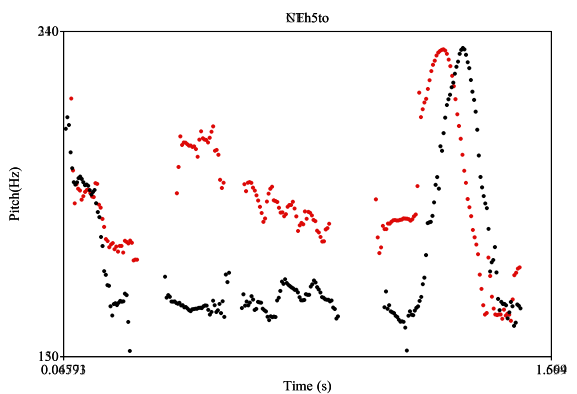

(b)

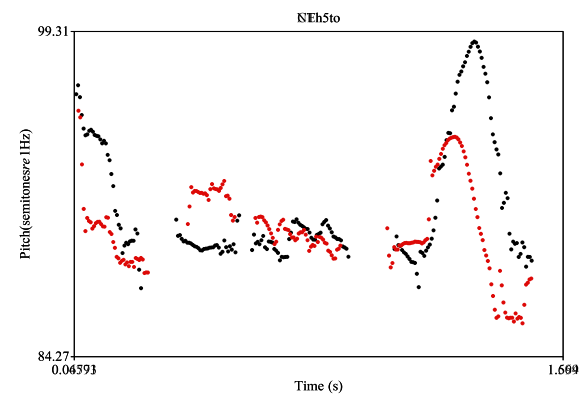

Figura 6: Curvas de F0 de duas produções sobrepostas desenhadas usando escalas verticais diferentes: (a) valores em hertz; (b) valores normalizados em semitons

Os valores de F0 das sentenças do segundo experimento foram então normalizados, convertendo-se as medidas de hertz para semitons. Segundo T'Hart (1981 apud MARTINS; FERREIRA NETTO, 2010), uma mudança de três semitons já é considerada uma variação tonal perceptivelmente relevante para os ouvintes do holandês. Testes realizados por Consoni et al. (2009) mostraram que os sujeitos brasileiros percebem com acuidade variações ascendentes a partir de três semitons. Observando as curvas em semitons, podem-se ver as mudanças na curva de F0 que são efetivamente percebidas pelos ouvintes. Desse modo, pode-se fazer o cruzamento entre o movimento apresentado por cada tipo de foco aqui investigado e as variações na quantidade de semitons que seriam consideradas perceptivelmente relevantes para os ouvintes. Para a análise dos dados, segmentamos as palavras da sentença e, na palavra focalizada, segmentamos as sílabas. Além disso, também eliminamos as curvas de F0

14 Range é o termo usado para descrever a faixa que compreende os valores mínimo e máximo da frequência fundamental de um determinado enunciado. 
do foco exaustivo (20 sentenças), pois a maior parte delas se assemelhava ao padrão das declarativas neutras do português (uma sentença com foco amplo), e não a uma sentença com foco estreito, como as que estamos estudando. Para confirmar essa hipótese, é preciso fazer um estudo comparativo da exaustividade com sentenças declarativas neutras, possibilidade que consideramos para uma pesquisa futura. A partir dessas constatações, ficaram para investigação, no experimento de produção e de percepção, 40 sentenças.

\section{Resultados do novo experimento de produção}

Resumidamente, a análise dos dados do novo experimento de produção nos mostra que a prosódia tem papel fundamental na marcação de foco em $\mathrm{PB}$, mas que a sintaxe também é muito importante nesse processo.

Quanto aos resultados relacionados à curva de F0, considerando-se o movimento do pico de F0 - ou seja, o movimento de maior proeminência - nas sentenças que tinham foco marcado no sujeito ou no objeto, percebeu-se que a proeminência da curva de F0 ficava bastante evidente sobre o elemento focalizado. No elemento focalizado (sujeito ou objeto), podíamos ter: (i) o movimento do pico de F0 à esquerda da sílaba tônica, apresentando um movimento ascendente na pré-tônica e descendente na tônica; (ii) todo o movimento do pico de F0 no centro da sílaba tônica, isto é, a subida e a descida da curva de F0 acontecem dentro da sílaba tônica; (iii) ou ainda o movimento do pico de F0 à direita da sílaba tônica, apresentando um movimento de subida na tônica (movimento ascendente) com queda da curva a partir da sílaba pós-tônica. Com o foco sobre o objeto, a curva de F0 era bastante irregular no início da sentença. Às vezes, os falantes produziam dois picos de F0, um no sujeito e outro no objeto, que era o item lexical que recebia o foco. Esse comportamento pode ser explicado considerando que, para o $\mathrm{PB}$, os falantes optam por não produzir sentenças com estrutura SVO para marcar foco no objeto, preferindo mover o objeto para receber o acento de foco com o uso de uma sentença clivada ${ }^{15}$ ou de suas variações (QUAREZEMIN, 2009). Entretanto, nossos informantes não puderam fazer isso devido ao fato de terem de reproduzir

\footnotetext{
15 Clivadas são sentenças focalizadoras, compostas de cópula (verbo ser) + elemento focalizado + complementizador (que) + sentença encaixada. Por exemplo: Foi o João que comeu o bolo.
} 
sentenças pré-determinadas, não podendo escolher a estrutura da sentença que produziriam. Essa situação pode ter sido a causa das irregularidades observadas.

Quando o foco da sentença estava no sujeito, era ele que recebia o pico de F0 e depois a curva era descendente, como previsto na literatura (MORAES, 1991; FERNANDES, 2007).

Levando em conta o mecanismo de focalização observado em nossos dados, verificamos que, como no PB os constituintes tanto têm flexibilidade para se locomover dentro da sentença e receber acento de foco (foco marcado por meio de uma sentença clivada, por exemplo, fazendo a marcação de foco por meio da sintaxe) quanto para manter os constituintes in situ na estrutura SVO (fazendo a marcação por meio da prosódia), nossos informantes não estranharam nenhuma das sentenças que tiveram de gravar, nem mesmo as sentenças que ouviram para identificar a mais adequada. Houve manifestações apenas quanto à possibilidade de usar marcadores lexicais, como o "não" e o "só" (que, como são advérbios focalizadores, destacam o foco na sentença).

Essas observações ratificam o que foi verificado em Quarezemin (2009), a saber, que o PB parece permitir duas maneiras de marcar o foco: uma que exibe flexibilidade na ordem dos constituintes das sentenças, como acontece no português europeu e no italiano; e outra, que parece ter uma posição sintática destinada aos constituintes focalizados, como acontece no inglês e no francês. Nossos dados mostraram essas duas possibilidades, pois o comportamento irregular quando o foco recai sobre o objeto ${ }^{16}$ parece reforçar a necessidade de deslocamento desse item sintático. No entanto, o não estranhamento dos falantes quanto aos focos realizados a partir da entoação reforçam que, no PB, as duas situações parecem ser possíveis, ou seja, deslocamento do objeto para a marcação do foco pela sintaxe ou marcação do foco pela prosódia quando a estrutura da sentença é SVO (especialmente quando o item focalizado é o sujeito). Isso parece evidenciar que prosódia e sintaxe têm papel fundamental no processo de focalização em PB.

\footnotetext{
${ }^{16}$ Como já salientamos, o fato de a posição final da sentença ser também a posição default do acento tonal pode ser a causa desse comportamento, já que teríamos aí dois contornos em disputa: o da asserção neutra e o do foco no objeto.
} 


\section{Novo experimento de percepção}

Para testarmos os resultados do novo experimento de produção, montamos também um novo experimento de percepção. Além de observar as curvas de F0, nesse novo experimento de percepção procuramos verificar até que ponto a duração das sílabas estaria ligada à identificação de um determinado tipo de foco.

Primeiramente, fizemos mais uma modificação na nossa metodologia de pesquisa. A dificuldade de controlar todas as variáveis nesse tipo de experimento nos levou a reproduzir em laboratório as sentenças para o novo experimento de percepção. Nos experimentos piloto de percepção, por exemplo, o contexto era gravado com uma voz e, geralmente, as sentenças a serem avaliadas perceptualmente eram proferidas por falantes diferentes (resultando numa avaliação com base em três vozes diferentes para cada comparação), e nos perguntamos se isso poderia influenciar na análise subjetiva do ouvinte. Assim, a reprodução em laboratório dos contextos narrativos e das sentenças nos dá as seguintes vantagens: (i) maior controle das variáveis relacionadas à duração das sílabas e ao movimento da curva de F0 e (ii) a voz do contexto narrativo e das sentenças ouvidas seria a mesma, o que achamos que poderia dar mais naturalidade ao experimento. Então, as sentenças utilizadas no experimento de percepção, assim como já tinha sido feito com os contextos narrativos, foram gravadas por um dos pesquisadores. Nessas gravações, foram reproduzidos os padrões de curva de F0 e de duração apresentados nas gravações dos informantes do experimento de produção. A partir dessas estratégias, montamos um experimento com 24 estímulos que era composto da combinação de um contexto narrativo com um par de sentenças (da mesma forma que os dois experimentos piloto de percepção descritos anteriormente) em fala natural.

Participaram desta etapa sete ouvintes, com nível superior completo e incompleto (em andamento), sendo cinco mulheres e dois homens, com idades entre 23 e 48 anos, da região da Grande Florianópolis. Os 24 estímulos do experimento foram apresentados aos sete participantes, resultando em 168 julgamentos coletados. 


\section{Resultados do novo experimento de percepção}

Neste experimento, $76 \%$ dos ouvintes relacionaram as sentenças com contorno de não exaustividade aos contextos de não exaustividade, e $80 \%$ fizeram o mesmo com as curvas e os contextos de contrastividade. Como os ouvintes demonstraram perceber diferença entre as sentenças, identificando seus respectivos focos, analisamos quais seriam essas diferenças entre as produções para tentar identificar qual parâmetro forneceu aos ouvintes a pista para perceberem quando uma sentença veiculava foco não exaustivo e quando veiculava foco contrastivo.

O que fica evidente na análise das oito curvas de F0 que compõem o experimento é que as sentenças com foco não exaustivo têm pitch range mais alto, em média quatro semitons. O contorno de F0 e mesmo a descrição dos movimentos das curvas de F0 (apresentada anteriormente) do foco não exaustivo e das curvas do foco contrastivo são muito semelhantes, mas há uma diferença de altura no foco não exaustivo, como também vêm demonstrando os estudos conduzidos por Elordieta e Irurtzun (2010) sobre a língua basca. Então, parece-nos que o pitch range seria pelo menos um dos parâmetros (considerando que haja outros) que caracterizam e diferenciam a curva de $\mathrm{F} 0$ da não exaustividade, já que as sentenças com foco não exaustivo alcançavam range mais alto do que as sentenças com foco contrastivo.

Essa percepção está baseada na diferença média entre as sentenças com focos não exaustivo e contrastivo que compuseram o novo experimento de percepção, que era de 4 semitons a mais para as curvas com foco não exaustivo, o que, como mostraram os estudos de Consoni e Ferreira Netto (2008) para o PB e de T'Hart (1981 apud MARTINS; FERREIRA NETTO, 2010) para o holandês, já é percebido pelos ouvintes. Dessa forma, observamos que parece sim existir uma curva de F0 característica de sentenças com foco não exaustivo, ou seja, a prosódia, aliada ao contexto, dá conta de veicular a ideia de não exaustividade, sem a obrigatoriedade da presença de marcadores lexicais que a reforcem - e nesses casos, sem marcação sintática, uma vez que todas as sentenças tinham a mesma estrutura.

A análise sobre a duração das sílabas mostrou que os ouvintes apontaram como mais adequadas para os contextos de não exaustividade as sentenças com duração semelhante entre sílaba tônica e sílaba pré-tônica (57\% das respostas). No caso da 
contrastividade, porém, em $57 \%$ dos casos os ouvintes deram respostas que indicam que a duração das sílabas não é critério para a marcação da contrastividade, pois não relacionaram nenhum tipo de duração específica com esse tipo de focalização, aceitando igualmente todas as variáveis de duração apresentadas.

\section{Outros experimentos em andamento}

Neste momento, outro experimento está sendo preparado, com modificações que julgamos necessárias após a nova rodada de experimentos já mencionada. Entre as mudanças previstas estão: a) inclusão de análise estatística dos dados e b) gravação de áudio e vídeo, pois vamos correlacionar a prosódia da fala com a prosódia visual.

Como nossos primeiros experimentos já nos forneceram dados indicando que existe um comportamento prosódico específico para os diferentes tipos de foco, nossas hipóteses agora são de que também haveria particularidade nos gestos faciais para os diferentes tipos de foco e que a prosódia da fala somada à prosódia visual (movimentos faciais simultâneos à produção da fala) vai nos dar mais pistas sobre a marcação e, principalmente, a percepção do foco.

Menuzzi (2012) acredita que a focalização seja um fenômeno pragmático, e não prosódico. Para o autor, a prosódia seria capaz apenas de marcar que um sintagma ou uma sentença recebe marcação de foco, mas não de indicar qual seria o tipo de foco. Carpes, Sosa e Seara (2013) e Carpes (2014), porém, conduziram experimentos de produção e percepção que indicam o contrário: a prosódia sozinha é capaz, muitas vezes, de marcar o tipo de foco veiculado na sentença, como apontam os resultados apresentados neste artigo.

Nossa segunda hipótese é de que a focalização em PB seja uma combinação de prosódia (da fala e visual), sintaxe, pragmática e, algumas vezes, léxico.

\section{Sobre a prosódia visual}

Durante uma conversa, os falantes frequentemente movimentam o corpo e fazem gestos faciais. Muitas das expressões faciais e deslocamentos da cabeça estão atrelados à estrutura prosódica. Nesses casos, esses movimentos funcionam como uma prosódia visual. (PACHECO, 2011, p. 1). 
Os movimentos que o falante faz em sintonia com a fala, sejam eles faciais ou corporais, funcionam como complemento da linguagem verbal. Há alguns parâmetros a serem considerados na análise da prosódia visual, tais como: movimentos de sobrancelha (levantamento e abaixamento); movimentos de olhos (abrir, fechar, piscar, semicerrar, direção do olhar); movimentos de cabeça (cima-baixo, baixo-cima, frentetrás, trás-frente, inclinação); movimentos de ombros (levantar, abaixar).

Os gestos faciais ou corporais seguiriam a entoação, ou seja, coincidiriam com a melodia da fala. Muitos estudos sugerem que movimentos de cabeça estariam ligados a questões suprassegmentais, como acento ou ênfase, por isso acreditamos que a investigação da prosódia visual pode trazer contribuições importantes para a descrição dos processos de focalização, pois "esses movimentos faciais e corporais não são meros movimentos realizados ao acaso pelo falante, mas, pelo contrário, eles carregam consigo uma informação linguística, em particular, de cunho prosódico" (PACHECO, 2011, p. 1).

Cada vez mais pesquisadores da área da prosódia têm reconhecido a importância de incluir a prosódia na modalidade visual em seus estudos, por verem o quanto essa modalidade de análise melhora a percepção de marcadores de fala, como tomada de turno, foco, emoções, atitudes e outros tipos de ênfase que o falante deseje acrescentar à sua elocução (MORAES; MIRANDA; RILLIARD, 2012; MORAES; RILLIARD, 2014).

Pesquisas desenvolvidas por outros estudiosos mostram dados que indicam que sinais de cabeça contribuiriam para a segmentação do contínuo da fala, desempenhando um papel importante no processamento audiovisual da fala (PACHECO, 2012; MUNHALL et al., 2004).

Esses são os motivos que nos farão, na próxima etapa da pesquisa, incluir a coleta e a análise de vídeo junto com a coleta e a análise do áudio dos falantes. Buscaremos descrever os parâmetros prosódicos da fala e dos sinais visuais que o falante transmite ao interlocutor, bem como testar em experimentos de percepção o reconhecimento e a identificação desses parâmetros na produção de sentenças com foco em PB. 


\section{Nova metodologia experimental: coleta de dados de produção}

Com o objetivo de aperfeiçoar nossa metodologia, melhorar a qualidade do nosso corpus e obter dados de análise mais confiáveis, neste experimento de produção vamos gravar áudio e vídeo das conversações. A metodologia prevê que o informante agora vai interagir com o pesquisador, e não apenas ouvir contextos gravados. Com isso, pretendemos conferir mais naturalidade à fala do informante. Nas rodadas anteriores, os informantes ficavam sozinhos numa sala interagindo apenas com o computador enquanto rodavam o experimento, o que está longe de se aproximar de um contexto real de fala.

O informante vai estar em uma sala com um dos pesquisadores, tendo um monitor de computador virado apenas para si. O pesquisador não verá a informação fornecida pelo monitor. $\mathrm{O}$ informante vai ler uma sentença que depois desaparecerá da tela e em seguida o pesquisador lhe fará uma pergunta, e o informante irá responder de acordo com a informação dada pelo computador. As perguntas têm como objetivo direcionar o foco prosódico a ser produzido pelo informante.

O conteúdo será exibido de forma aleatória, e o pesquisador vai informar ao participante que ele desconhece o conteúdo que aparece na tela. Serão dadas instruções ao participante sobre a estrutura sintática das sentenças que ele deverá produzir como resposta, de modo a serem gravadas sentenças do tipo SVO, sem o uso de advérbios, como "não" ou "só", por exemplo, pois, para estabelecer comparações entre as produções dos falantes, eles precisam dizer as mesmas sentenças. Para isso, será feita uma rodada de familiarização com o experimento antes da coleta propriamente dita, para que o informante entenda o procedimento. A rodada de familiarização é uma etapa importante da coleta de dados, pois dá ao pesquisador mais segurança de que o informante entendeu como será o experimento. Sem essa rodada de apresentação, o participante vai entendendo a dinâmica do teste enquanto ele está sendo feito. Dessa forma, os primeiros dados coletados podem não ser tão confiáveis, pois o informante poderia ainda não ter entendido o procedimento. Serão incluídas algumas sentenças distratoras, para evitar que o informante identifique o objeto de estudo.

O participante falará com o pesquisador, e uma câmera de vídeo será posicionada de frente para o participante, para captar os movimentos faciais que ele 
produzir. Também será usado um microfone para que a coleta de áudio seja feita com qualidade. Ao final da coleta, o participante preencherá um questionário para que faça uma avaliação subjetiva da sua participação no experimento, indicando o grau de dificuldade de compreensão e execução da atividade.

Todas essas mudanças metodológicas têm como objetivo fornecer melhores dados de análise, além de oferecer instrumentos mais precisos que permitam tornar mais confiável a nossa metodologia de trabalho, o que nos possibilitará desenvolver com mais segurança a base empírica de nossas teorias.

[...] pensar experimentalmente uma questão, definindo explicitamente as hipóteses, as variáveis independentes e dependentes, procurando controlar as variáveis estranhas, estabelecendo com rigor os materiais, as tarefas experimentais e os grupos de sujeitos, adotando análises estatísticas apropriadas, tem um efeito extremamente benéfico para o próprio pensar teórico, que passa a ser mais rigoroso e criterioso. (MAIA, 2012, p. 186).

Cada participante vai gravar as mesmas sentenças quatro vezes. Além da comparação entre falantes, vamos fazer uma comparação intrafalante, comparando entre si as produções dos falantes com o objetivo de verificar se eles reproduzem em todas as rodadas os mesmos padrões prosódicos, tanto na fala quanto visualmente.

A descrição da fala será feita seguindo o procedimento já mencionado nos resultados aqui apresentados. A descrição dos movimentos faciais seguirá o Facial Action Coding System (FACS), sistema desenvolvido para descrever expressões faciais humanas, criado por Ekman e Friesen (1978).

A princípio, vamos nos concentrar na descrição de pistas visuais da região superior do rosto dos informantes. Em pré-testes informais que realizamos, percebemos que a região dos olhos e da sobrancelha são as que parecem apresentar movimentos com maior proeminência, ou seja, de maneira mais enfática, no momento da produção dos sintagmas focalizados. Swerts e Krahmer (2008) conduziram experimentos de percepção em prosódia visual com falantes do alemão e testaram os graus de identificação de porções faciais, dividindo a análise entre rosto inteiro, apenas a parte superior, apenas a parte inferior, apenas o lado esquerdo e apenas o lado direito. Os resultados mostram que a área facial superior tem um valor de sinalização mais forte que aumenta o grau de identificação das palavras com mais proeminência em uma 
sentença do que a parte inferior. Como vamos gravar imagens dos informantes a partir da porção peitoral (incluindo ombros e cabeça), caso nos pareça importante incluir outros pontos de descrição visual, nós poderemos fazê-lo.

O software usado para apresentar as informações ao participante durante o experimento de produção será o Microsoft PowerPoint. Tentamos usar um script para o Praat, mas encontramos um problema para aleatorizar os dados. Nesse novo experimento, o pesquisador precisa saber qual a ordem de aparição das sentenças para o informante para que ela faça a pergunta adequada que o faça produzir a sentença esperada. Com o uso do Praat isso não seria possível, uma vez que, a cada rodada, o programa sozinho aleatoriza os dados, de modo que o pesquisador não teria como saber o que está aparecendo na tela para o informante.

Assim, a solução encontrada consiste em usar slides do Microsoft PowerPoint e fazer a aleatorização dos dados manualmente. O procedimento terá as seguintes etapas: numerar sequencialmente os slides com as informações que aparecerão para $\mathrm{o}$

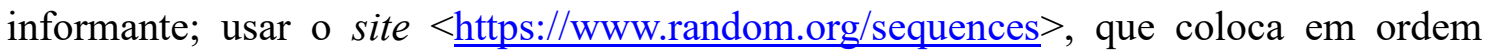
aleatória uma sequência numérica dada; gerar uma sequência diferente para cada rodada de coleta; colocar os slides em ordem aleatória manualmente no PowerPoint, seguindo aquela ordem fornecida pelo site mencionado; gerar um arquivo de slides diferente para cada rodada de coleta.

Abaixo um exemplo do procedimento para a produção da sentença "A Vanusa ensina desenho", com foco exaustivo. O participante lê na tela a informação em (7) e em seguida o pesquisador faz a pergunta apresentada em (8). A sentença que o participante deve proferir está em (9), com o foco sobre o sintagma em negrito.

(7) É só a Vanusa que começa o desenho, mais ninguém.

(8) Quem é que começa o desenho?

(9) A Vanusa começa o desenho.

Após todos os dados coletados e o experimento de produção ter sido analisado e descrito, vamos rodar testes estatísticos e definir o corpus do experimento de percepção. Vamos ainda investigar mais a fundo os parâmetros de duração das sílabas e o 
alinhamento do pico da curva de F0, fazendo a normalização dos valores de F0, usando semitons, para estabelecer comparações mais precisas.

\section{Perfil sociolinguístico dos participantes e número de sentenças do corpus}

Para a rodada piloto que vai testar esta nova metodologia de coleta, serão recrutados oito informantes, todos mulheres, de duas cidades de diferentes regiões do estado de Santa Catarina: quatro mulheres de Florianópolis e quatro mulheres de Blumenau. O perfil sociolinguístico dessas mulheres prevê que todas tenham nível universitário (graduação em andamento no mínimo) e idades entre 20 e 35 anos.

O número de sentenças total é nove: serão três sentenças com o mesmo conteúdo segmental produzidas com os três tipos de foco sob investigação. Cada informante gravará as sentenças quatro vezes. Assim, o número total de sentenças coletadas para análise no experimento piloto será 288: 8 sujeitos $\times 3$ sentenças $\times 3$ tipos de focos $\times 4$ repetições.

\section{Nova metodologia de coleta para o experimento de percepção}

Uma nova ferramenta será usada para rodar o experimento de percepção: o software $\mathrm{TP}^{17}$, o qual nos permite apresentar aos participantes dados de áudio e vídeo ao mesmo tempo.

Como queremos testar a influência da prosódia auditiva e da prosódia visual, vamos montar três tipos de testes de percepção: um apenas com os estímulos sonoros; outro apenas com os estímulos visuais; um terceiro com a combinação de estímulos sonoros e visuais.

Essas três combinações serão apresentadas a diferentes avaliadores. Depois vamos comparar seus resultados. Nossa hipótese é de que a percepção do foco aumente nesta ordem: apenas estímulos visuais, apenas estímulos sonoros, combinação de estímulos sonoros e visuais. Também vamos montar estímulos que combinam dados incongruentes para ver como os participantes reagem quando áudio e vídeo produzidos em contextos diferentes são combinados como se tivessem sido produzidos juntos.

${ }^{17}$ Software gratuito disponível em: $<$ http://www.worken.com.br/tp_regfree.php $>$. 
[...] marcadores visuais de proeminência (como movimentos de sobrancelha, acenos de cabeça ou velocidade e amplitude de movimentos articulatórios) podem desempenhar uma função semelhante à dos acentos de pitch, confirmando a expectativa de que uma posição correta [movimento adequado] proporcionará uma melhora no processamento da fala pelos ouvintes, enquanto posições incorretas [movimentos inadequados] podem prejudicar tal processamento. (SWERTS, KRAHMER, 2008, p. 228, tradução nossa). ${ }^{18}$

Da mesma forma que será feito no experimento de produção, os informantes realizarão o teste mais de uma vez, para verificarmos se eles confirmam a primeira interpretação.

\section{Considerações finais}

Nosso percurso na pesquisa sobre a focalização em PB nos conduziu a achados importantes sobre esse fenômeno na nossa língua. Os resultados obtidos já são bastante significativos e nos inspiram a seguir os desafios que ainda se apresentam, para obtermos novas informações que contribuirão para a pesquisa dos processos de focalização em estudos fonéticos e de interface.

Os experimentos de produção e percepção aqui descritos já apresentam dados suficientes para indicar que a prosódia tem importante papel na marcação do foco em PB. Também foram descritas as etapas dos próximos experimentos, agora ainda mais abrangentes, uma vez que somam à pesquisa a prosódia visual. Nessa caminhada metodológica, aprendemos com erros e acertos e nos sentimos motivados a continuar trilhando esse percurso, que certamente trará contribuições valiosas para os estudos linguísticos.

Agradecimentos: Ao Conselho Nacional de Desenvolvimento Científico e Tecnológico (CNPq), pelo financiamento de parte desta pesquisa. Aos pareceristas anônimos desta revista, pela leitura rigorosa e pelos comentários ao texto original que, certamente, contribuíram para uma versão mais adequada do artigo. Salientamos, no entanto, que possíveis inadequações remanescentes são de nossa inteira responsabilidade.

${ }^{18}$ Do original: "[...] visual markers of prominence (such as eyebrow movements, head nods, or the velocity and amplitude of articulatory movements) can perform a similar function as pitch accents, confirming the expectation that a correct placement will enhance the listeners' processing of incoming speech, while incorrect placements may hinder it.". 
CARPES, Daise Ribeiro Pereira; SEARA, Izabel Christine. Methodological strategies to investigate focus prosody in Brazilian Portuguese (BP). Revista do Gel, v. 14, n. 2, p. 125-156, 2017.

Abstract: This paper discusses the development of corpora for prosodic analysis of nonexhaustive, exhaustive and contrastive foci in Brazilian Portuguese. We described the methods of production and perception experiments created to investigate and describe the speech prosody and the visual prosody of declarative sentences with the three types of aforementioned foci, considering the hypothesis that there are different prosodic behaviors for different types of focus. We perform a methodological description of the experiments already carried out as well as the description of the first findings and the next experimental steps.

Keywords: Phonetics. Prosody. Focus. Visual prosody. Experimental Linguistics.

Submetido em: 17/09/2016.

Aceito em: 07/05/2017.

\section{Referências}

CARDOSO, S. A. et al. Atlas Linguístico do Brasil. Cartas linguísticas. v. 2. Londrina: EDUEL, 2014.

CARNAVAL, M. Foco informacional e foco contrastivo no português do Brasil: uma abordagem prosódica. 2017. 153 f. Dissertação (Mestrado em Letras Vernáculas) Faculdade de Letras, Universidade Federal do Rio de Janeiro, Rio de Janeiro, 2017.

CARPES, D. R. P. Um estudo prosódico-semântico da não exaustividade no português brasileiro. 2014. 107 f. Dissertação (Mestrado em Linguística) Universidade Federal de Santa Catarina, Centro de Comunicação e Expressão, Programa de Pós-graduação em Linguística, Florianópolis, 2014. Disponível em:

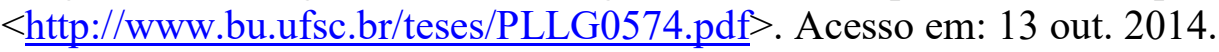

CARPES, D. R. P.; SOSA, J. M.; SEARA, I. C. Experimento de produção sobre a prosódia da não exaustividade no português brasileiro. Revista Leitura, n. 52, v. 2, jul./dez. 2013. p. 165-184. Disponível em:

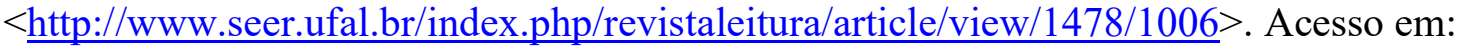
13 jul. 2013.

Perception of tonal contrasts of non-exhaustivity in Brazilian Portuguese: an experimental study. $4^{\text {th }}$ International Symposium on Tonal Aspects of Languages (TAL). Nijmegen, Holanda; p. 108-111, 2014. Disponível em: $<$ http://www.iscaspeech.org/archive/tal_2014/t114_108.html>. Acesso em: 13 jun. 2016. 
CHOMSKY, N.; HALLE, M. The sound pattern of English. New York: Harper and Row, 1968.

CONSONI, F.; PERES, D.; LASSAK, A.; ROSA, R.; FERREIRA NETTO, W. Sensitivity to F0 variation in Brazilian Portuguese. Proceedings of 40th Poznan Linguistic Meeting. Poznan, 2009.

EKMAN, P.; FRIESEN, W. Facial action coding system: a technique for the measurement of facial movement. Consulting Psychologists Press: Palo Alto, 1978.

ELORDIETA. G. Constraints on Intonational Prominence of Focalized Constituents. In: LEE, C.; GORDON, M. (Ed.). Topic and Focus: Cross-Linguistic Perspectives on Meaning and Intonation. Springer, 2007. p. 1-22.

ELORDIETA, G.; IRURTZUN, A. The relationship between meaning and intonation in non-exhaustive answers: Evidence from Basque. The Linguistic Review, 2010, v. 27, n. 3. p. 261-291. Disponível em:

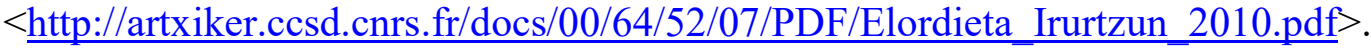

Acesso em: 10 jan. 2013.

FERNANDES, F. R. Tonal association of neutral and subject-narrow-focus sentences in Brazilian Portuguese: a comparison with European Portuguese. Journal of Portuguese Linguistics, Campinas, p. 91-115, 2007.

FROTA, S. Prosody and focus in European Portuguese: phonological phrasing and intonation (outstanding dissertations in Linguistics). New York: Garlang Publishing, 2000 .

KISS, K. Identificational focus versus information focus. Language. v. 74, n. 2, p. 245 273, 1998. Disponível em:

$<$ https://muse.jhu.edu/content/crossref/journals/language/v074/74.2.kiss.html $>$. Acesso em: 17 mai. 2016.

SWERTS, M.; KRAHMER E. Facial expression and prosodic prominence: Effects of modality and facial area. Journal of Phonetics. v. 36, n. 2, 2008, p. 219-238.

Disponível em:

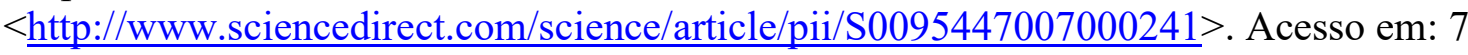
jul. 2016.

LADD, D. R. Intonational phonology. Cambridge: Press Syndicate of the University of Cambridge, 2008.

MAIA, M. Sintaxe experimental: uma entrevista com Marcus Maia. ReVEL, v. 10, n. 18, p. 184-193, 2012. Disponível em: $<$ http://www.revel.inf.br/files/6935cf63f254321891e9df0d88ad1a13.pdf $>$. Acesso em: 7 mai. 2016. 
MARTINS, M. V. M.; FERREIRA NETTO, W. Prosódia e escalas de frequência: um estudo em torno da escala de semitons. ReVEL, v. 8, n. 15, p. 286-296, 2010.

Disponível em:

$<$ http://www.revel.inf.br/files/artigos/revel_15 prosodia_e_escalas_de_frequencia.pdf $>$. Acesso em: 8 mai. 2016.

MENUZZI, S. M. Algumas observações sobre foco, contraste e exaustividade. In: Revista Letras, Curitiba (Editora UFPR), n. 86, p. 95-121, jul./dez. 2012. Disponível em: <http://ojs.c3sl.ufpr.br/ojs2/index.php/letras/article/viewFile/29909/199 07>. Acesso em: 2 mai. 2013.

MIOTO, C. Focalização e quantificação. Revista Letras, Curitiba (Editora UFPR), v. 61, p. 169-189, 2003.

MORAES. J. A. Intonation in Brazilian Portuguese. HIRST, D.; DI CRISTO, A. Intonation Systems: a survey of twenty languages. Cambridge: Cambridge University Press, 1991. p. 179-194.

. Variações em torno de tema e rema. In: Cadernos do CNLF, v. IX, n. 17, p. 279-289, 2006. Disponível em: <http://www.filologia.org.br/ixcnlf/17/23.htm>. Acesso em: 2 mai. 2013.

MORAES, J. A.; CARNAVAL, M.; COELHO, A. B. B. A manifestação prosódica do foco em interrogativas totais no português do Brasil e sua percepção. ReVEL, edição especial, n. 10, p. 170-194, 2015. Disponível em:

$<$ http://revel.inf.br/files/25628f323ed484f9952532a1604fbb93.pdf $>$. Acesso em: 10 mai. 2017.

MORAES, J. A.; RILLIARD, A. Illocution, attitudes and prosody. In: RASO, T., MELLO, H. (Ed.). Spoken Corpora and Linguistic Studies. Amsterdam: John Benjamins, 2014.

MORAES, J. A.; MIRANDA, L.; RILLIARD, A. Expressões faciais na manifestação de atitudes prosódicas do Português do Brasil. Trabalho apresentado no GSCP 2012 International Conference. Belo Horizonte, 2012. Disponível em:

$<$ http://150.164.100.248/gscp2012-eng/data1/arquivos/gscp2012_submission_96.pdf $>$. Acesso em: 30 mar. 2017.

MUNHALL, K. G. et al. Visual prosody and speech intelligibility: head movement improves auditory speech perception. Psychological Science, v. 15, n. 2, p. 133-137, 2004.

PACHECO, V. Percepção de ênfase e atenuação: o papel dos movimentos faciais e corporais. Anais do III Colóquio Brasileiro de Prosódia da Fala. 2011. Disponível em:

$<$ http://www.periodicos.letras.ufmg.br/index.php/anais_coloquio/article/view/1263/137 7>. Acesso em: 29 jun. 2016. 
PIERREHUMBERT, J. The Phonology and Phonetics of English Intonation.

Cambridge: Massachusetts Institute of Technology, 1980.

QUAREZEMIN, S. Estratégias de focalização no português brasileiro. 2009. 198 f. Tese (Doutorado em Linguística) - Pós-graduação em Linguística, Universidade Federal de Santa Catarina, Florianópolis, 2009.

SEARA, I. C.; FIGUEIREDO-SILVA, M. C. Metodologia para descrição da entoação na interface sintaxe-fonologia. Revista Intercâmbio, São Paulo (LAEL/PUC-SP), v. XVI, p. 1-21, 2007.

SERRA, C. R. Realização e percepção de fronteiras prosódicas no Brasil: fala espontânea e leitura. 2009. 241 f. Tese (Doutorado em Letras Vernáculas) - Programa de Pós-graduação em Letras Vernáculas, Universidade Federal do Rio de Janeiro, Rio de Janeiro, 2009.

ZUBIZARRETA, M. L. Prosody, focus and word order. Cambridge: MIT Press, 1998 . 